a sudden pain in the upper part of the belly', which caused her to faint; this was followed by general abdominal pain and vomiting. The next day the doctor who saw her, having diagnosed the case as one of perforated gastric ulcer, advised her removal to hospital.

Condition on Admission.-She appeared somewhat collapsed ; temperature 99.4 F.; pulse 1 10. The abdomen was rigid and tender. She complained of general abdominal pain and pain in the back. Liver dulness was present, and there was but moderate distension. The bowels had acted on the morning of December 22nd, but there had been no action or passage of flatus since the onset of the illness.

Operation.-I saw the case shortly after admission, agreed with the diagnosis, and, after consultation with other members of staff, decided to operate. At 6 P.M. (twenty-eight hours after the rupture of the ulcer) $I$ opened the abdomen by an incision extending from the ensiform cartilage to the navel. The intestines were glued together by recent lymph and much turbid fluid was let out. This fluid seemed to come from near the pylorus, consequently the incision was enlarged by a transverse cut through the right rectus muscle. After carefully separating some of the adhesions, the pyloric end of the stomach was exposed, but no perforation found. The edge of the liver was then gently pulled up, and a small opening found on the anterior wall of the stomach, near the lesser curvature just below the osophageal opening. Round the perforation there was much induration and thickening of the stomach wall. The hole was closed by silk sutures, the abdomen simply sponged clean, and the wound closed in the ordinary way; a wick of cyanide gauze put in extending from the site of perforation to the upper part of the abdominal incision. In cleaning the peritoneal cavity, special care was taken to clean the subphrenic spaces. Liq. strych. miv was given hypodermically during the operation.

After-History.-The patient slept fairly well after an injection of morphine. Early the next morning she vomited slightly and several times during the day. She was fed by nutrient enemata every six hours, and nothing was given by the mouth until the fourth day, when small quantities of peptonised milk were given. The quantities were gradually increased, and the enemata discontinued on the sixth day after operation. She had no vomiting after the first twentyfour hours. Her temperature rose to $99.4^{\circ} \mathrm{F}$. on the third day after operation, but was otherwise normal or subnormal throughout. The bowels acted naturally on the second day, and gave very little trouble afterwards. The gauze plug was removed on the third day and a smaller one inserted. Afterwards the sinus was plugged daily till healing took place about a fortnight after operation. The patient was discharged cured on January 3ist, having made an uninterrupted recovery.

$1 \mathrm{am}$ indebted to Dr. G. H. Cowen, house-surgeon, for the notes of this case and also for his care in watching the patient.

\section{A CASE OF TUBerculous Disease OF THE CACUM,}

IN WHICH THE DISEASED PORTION OF INTESTINE WAS RESECTED.

By Lieutenant-Colonel J. MAITLAND, M.D., I.M.S. Professor of Surgery in the Madras Medical College.

Comparatively few operations for removal of the cæcum have been recorded. The earliest case reported was in 1884 by Mr. - Whitehead, who removed the cæcum for cancer, establishing an artificial anus. In the following year $\mathbf{M r}$. Sydney Jones removed the same portion of the bowel for malignant disease. In 1889, at the Congress at Bologna, Dr. Durante published a case, very similar to the one now re corded, of successful resection of the cæcum for tuberculous disease. He stated that Lawson Tait and Billroth had both performed operations for removal of the cæcum, but the nature of the disease was not stated. Dr. Trombetta at the same meeting reported a case performed by himself. In 1897 Dr. Crawford Renton excised the cæcum for "fistulæ," but the disease was not considered to be tuberculous in nature. The following are the notes of the case under record: A Hindu ryot, aged 44, was admitted into the Madras General Hospital
on January 2oth complaining of abdominal pain and constipation.
History. - The patient had enjoyed good health until eight years previous to admission into hospital, when he commenced to suffer from occasiona attacks of pain in the right side of the abdomen. These attacks came on at irregular intervals, were severe in character, and lasted for one or two hours at a time. On pressing with his hand over the right side of the abdomen the patient imagined he could feel a lump at the seat of pain. The used to come on about once a month or so, but they gradually became used to come on about once a month or so, but they gradually became About a year prior to admission, he began to suffer from attacks of disAbout a year prior to admission, he began to suffer from attacks of distension of the abdomen and retching arter taking food. in addition to his
other troubles. Constipation persisted, the bowels only acting by the aid other troubles. Constipation persisted, the bowels only acting by the aid
of the enemata. Latterly he had lost flesh considerably. $\mathrm{He}$ had never suffered from diarrhœa, nor had he ever passed blood by the rectum. The family history was unfavourable, the patient's father and one uncle having died of phthisis, and one of his nieces suffered from enlargement of the glands of the neck.

Condition on Admission. - The patient looked thin and ill, and there were symptoms of dyspepsia. Pain was more or less constant in the right side of the abdomen, and from time to time it became aggravated and very severe. The bowels only acted once in three or four days. there alway being some relief from pain afterwards. The circulatory and respiratory systems were healthy, and the urine normal. On examining the abdo men, it was found to be somewhat retracted except to the right of the umbilical region. where there was a visible swelling. On palpation a lump could be felt in this region, cylindrical in form, tapering off above and below. The upper end reached a point about an inch above the leve of the umbilicus. It was solid and firm in consistence, and tender on pressure, and could be rolled to a slight degree on its own axis, but could not be displaced in any direction. Pressure just below the swelling usually resonant.

usuaily resonant. - The physical signs as well as the symptoms of the case, considered in connection with the history, pointed to the existence of sidered in connection with the history, pointed to the existence of chronic disease of the cæcum or ascending colon, causing thickening of the bowel and possibly stenosis. The actual nature of the tumour was not diagnosed. The nature of the case having been explained

patient, he readily consulted to an operation being performed.
Operation.-The operation was performed on January 29 th, nine days after admission into hospital, the bowels in the meantime having after admission into hospital, the bowels in the meantime having been thoroughly cleared by means of castor oil. An incision abou 4 inches in length was made through the right linea semilunaris, and this incision was subsequently considerably enlarged in the upward
direction. On exposing the bowel, it was found to be not only much direction. On exposing the bowel, it was found to be not only much thickened, but also embedded in a mass of considerable thickness, and was bound down pretty firmly in the loin. Only a sinall area of the serous covering of the bowel remained uncovered, and this portion was its thick covering of tissue was with some difficulty freed from its attachments beneath, one large vessel giving some trouble before it could be secured. The whole of the diseased part of the bowel-which apparently consisted of ileum, cæcum, and part of the ascending colonwas then removed, having been previously isolated by clamps consisting of pieces of rubber tubing. The end of the divided large intestine was next closed by means of a continuous suture of silk passed through the mucous coat, covered by a row of Lembert sutures. The cut end of the stomosis effected by means of a Murphy button. The incision in the abdominal wall was closed by silkworm-gut sutures passed through all the layers, including the peritoneum. The patient bore the operation extremely well.

Description of Excised Bowel.-The portion of bowel removed was examined by Captain Fraser, the Pathologist to the hospital, who very amined by Captain Fraser, the Pathologist to the hospital, who very measures $1 \times \frac{1}{2}$ inches in length, and consists of $7 \frac{1}{2}$ inches of ileum and measures $11 \frac{1}{2}$ inches in length, and consists of $7 \frac{1}{2}$ inches of leum and 4 inches of cæcum and ascending colon. Around the lower part of the has become firmly adherent, forming an adventitious coat, which is stripped off with great difficulty. The wall of the intestine is thickened and hypertrophied, especially about the junction of the large with the small gut, where it measures an inch in thickness. The lumen of the gut at the ileo-crecal junction, where the wall is thickest, is greatly constricted and only admits a crowquill : while above this the lumen of the small intestine is dilated and appears about the size of the normal large intestine. Below the stricture the crcum and ascending colon are or normal size. The exact position of the ileo-cæcal valve cannot be determined as it seems to be involved in the cicatricial tissue about the ileo-crcal junction. cæcum is obliterated, and it has apparently become matted to the adherent omentum. The mucous lining of the cæcum shows an ulcerated adherent omentum. The mucous lining of the cæcum shows an ulcerated surface. A large irregularly oval ulcer I inch in diameter and transversely rough, with numerous small nodules, and its margins are thickened and rough, with numerous small nodules, and its margins are thickened and rleum. In the ileum the edges of the ulcers are swollen and undermined, and the bases are rough and show a number of greyish or yellowish-white firm nodules. Judging by the appearance of the intestine, the disease must have commenced in the cæcum, where

chronic character than do those in the ileum." The large pouch formed by the dilated portion of the ileum just above was al ways felt just below the lower end of the tumour.

wasalways fel just below the lower - The temperature rose on the fourth day to ror ${ }^{\circ}$, Progress of the Case. - The temperature rose on the fourth day to ror
but with this exception remained normal throughout. Loose motions bui with this exception remained normal throughout. Loose motions days, and subsequently regularly every diy. The Murphy button was passed on the fourteenth day. With the exception of water, nothing was given by the mouth until the eighth day. No solid food was given until the twenty-first day. The wound was dressed for the first time on the seventh day. It was then found that in the centre of the wound there was a portion about half an inch long which had not closed, but from the hospital, eight weeks after the operation, a small sinus re- 
mained unhealed. This led directly inwards for about an inch, and was probably connected with one of the silk ligatures which lay immediately probably connected with one of the silk ligatures which lay immediately patient was quite well.

The case presents several features of interest. As stated previously no decided opinion was formed prior to operation as to the nature of the disease affecting the bowel. The history was not that of recurring appendicitis, and the size and position of the tumour were opposed to such a diagnosis. This is mentioned because the case had been diagnosed as one of disease of the appendix, and the patient had been sent to hospital for operation on that account. The absence of any history of diarrhœa or hæmorrhage, and the presence of a distinct tumour negatived a diagnosis of ulceration of the bowel, and the disease was of too chronic a nature to be a cancer. The case serves to illustrate the fact that diarrhœa and hæmorrhage do not necessarily occur even when extensive ulceration of the cæcum exists. An interesting case, illustrative of the difficulty of diagnosis in these cases, is reported by Pilliet in the Progrès Médical of November, 1894 . In that case the tumour was considered by some to be a fibroid, by others an osteoma. When explored by operation it was incised, and found to be the cæcum affected with tubercle. No attempt was made to remove the diseased part. Stricture of the cæcum is very uncommon. Out of a series of 44 cases of stricture of the large intestine Treves only found 4 in the cæcum. Considering the narrowness of the stricture in this case, it is remarkable that there were not more definite signs of obstruction.

There is reason to think that tuberculous disease of the crecum is more common than is generally believed, and that some of these cases are mistaken for inflammatory conditions of the appendix. A very instructive case of this nature came under my care in hospital a few years ago. Before the patient came into hospital a swelling had formed at the site of the appendix, which was taken to be an appendicular abscess. The abscess had burst spontaneously, and after some time a fæcal fistula formed. When the patient came to hospital there was found to be considerable induration in the neighbourhood of the cæcum, and several fistulæ leading down to the indurated mass. A considerable quantity of pus and some fæcal matter was discharged from these fistulæ, and the pus tended to burrow in various directions. An exploratory operation was undertaken to see whether it was possible to close the communication with the bowel. The fistulæ and sinuses were laid open, but it was found that there was such extensive matting together of the parts that it was impossible to isolate the bowel from the surrounding structures. After a sufficient interval of time had elapsed a second operation was performed. The abdomen was opened and the affected portion of bowel was shut off from the rest of the alimentary canal by short circuiting, the lower end of the ileum being united to the transverse colon. The patient recovered from the operation, which was so far successful that all communication between the alimentary canal and the diseased portion of bowel was completely shut off. The sinuses, however, failed to heal, and pus continued to burrow in various directions in the iliac fossa and loin. The case was taken to be one of tuberculous disease of the intestines, and this opinion was strengthened by the fact that after a time a fresh fæcal fistula formed at the site of the second operation, ulceration of the bowel having taken place at this point.

The possibility of confusing cases of disease of the appendix with cases of tuberculous disease of the bowel itself was pointed out by Mr. Herbert Page a few years ago. Writing in the Lancet of July 3 rd, 1897 , he published a case very similar in many wass to the case under record, but in which the adhesions were too dense to admit of removing the diseased intestine. Cases like Mr. Page's, and the one previously operated on by myself, show that the difficulty of isolating the diseased portion of bowel may prove insuperable yet tho possibility of such a condition being present should not deter the surgeon from exploring the part.

When a reasonable suspicion of tubercle of the cæcum exists an exploratory operation should be undertaken, and should the surgeon's suspicions be confirmed an operation of this nature appears to offer a fair chance of pecovery from an otherwise incurable and distressing affection. The earlier the operation is undertaken the greater will be the likelihood of a successful issue.

\section{THR SPONTANEOUS CURE OF HYDATID CYSTS.}

By W. MITCHELL STEVENS, M.D.LoNd. Fellow of University College, London; Pathologist to the Cardiff Infirmary.

IT is well known that hydatid cysts which have undergone degenerative changes resulting in a "spontaneous cure" are not uncommonly found in the post-mortem room. An example of this condition occurring in the liver has lately come under my notice, and it, I think, throws some light on the vexed question of the causes leading to the death of the parasite:

The patient, a man aged 63 , died from the effects of an enlarged prostate. With the exception of the urinary organs, nothing abnormal was found at the necropsy until the liver was examined. This organ weighed 3 lbs. 15 ozs., and contained two cysts in different stages of diagram.

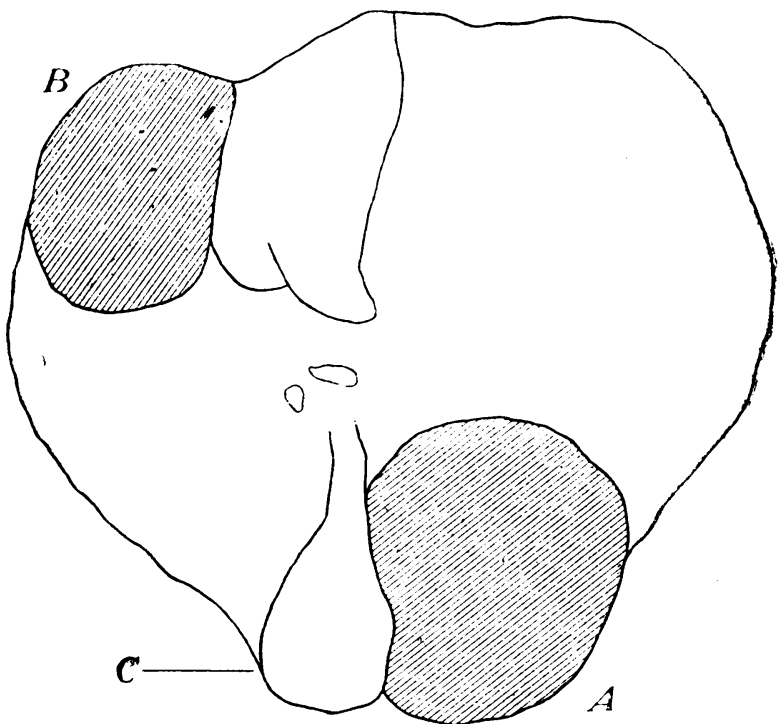

Lower surface of the liver; $A$, is the larger cyst; $B$, is the smaller cyst; $c$, gall bladder.

The larger cyst was about the size of an orange, and situated in the right lobe of the liver; its anterior wall did not project beyond the surface of the liver around it, but its posterior wall bulged considerably causing the cyst to have a tense globular appearance. The cavity of the cyst was completely filled with a uniform grey, putty-like mass. The capsule varied from $\frac{1}{4}$ to $\frac{1}{8}$ inch in thickness, and was composed of dense fibrous tissue. undergoing in parts calcareous changes, and on its inner surface was a thin, greyish-yellow, shaggy-looking deposit, which could easily be scraped off the fibrous tissue. The capsule in parts was comparatively easily separated from the hepatic tissue in contact with it and there were no signs of shrinkage. The putty-like mass was composed o granular debris, fatty material, crystals of cholesterine, and a few hooklets. The smaller cyst was situated in the left lobe of the iiver. Its capsule presented the same characteristics as the above described. Its contents, however, were in a different stage of degeneration, and the putty-like material was here mixed with a grey, translucent gelatinous substance, crescentic and folded layers of which were arranged in a concentric manner, and alternated with the thicker layers of pultaceous material The microscopical appearances of this cyst were similar to those of the other, and the grey gelatinous membrane presented the typical laminated character of the hydatid endocyst. Neither cyst contained bile. The liver itself was fibrous, and the microscope showed a general cirrhotic condition of the organ, most marked in the immediate neighbourhood of the cysts.

The chief points in the above cases are :

I. The two cysts were in different stages of degeneration; in the smaller one a quantity of the laminated hydatid membrane was still found, but in the other not a trace of this remained, and indeed nothing to indicate its nature except the presence of a few hooklets, which were only found after repeated examinations.

2. Both cysts were situated in the peripheral parts of the liver and projected considerably beyond its surface.

3. There were no evidences of pus in the contents of either cyst.

4. The capsules of the cysts were globular and tense, and there were no signs of puckering or contraction. 